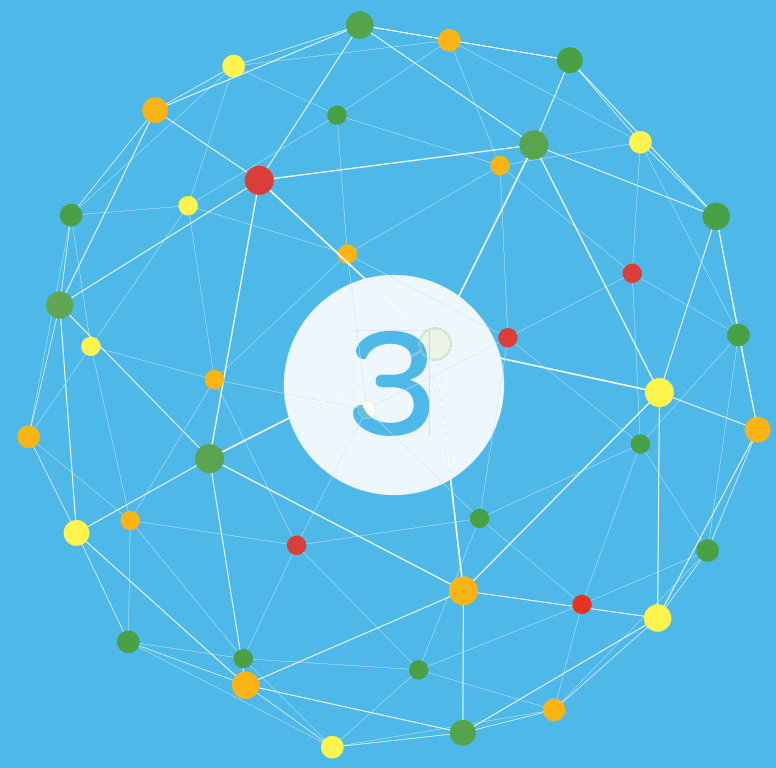

\title{
Policy Efforts and Monitoring Frameworks for the SDGs
}

